\title{
Picosecond-Laser Structuring of Thin Films for CIGS Solar Cells
}

\author{
Gediminas Račiukaitis, Paulius Gečys

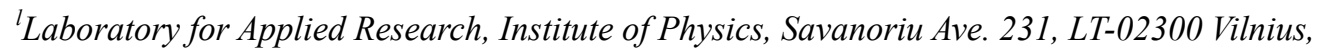 \\ Lithuania \\ E-mail: graciukaitis@ar.fi.lt
}

\begin{abstract}
Interest in complex multilayered $\mathrm{CuIn}_{\mathrm{x}} \mathrm{Ga}_{(1-\mathrm{x})} \mathrm{Se}_{2}$ solar cells has increased recently because of unique combination of factors such as low manufacturing cost and high photovoltaic conversion efficiency. The efficiency of the thin-film solar cells with a large active area might be maintained making series interconnects in order to reduce photocurrent in thin films and resistance losses. Laser technologies are a promising method to accomplish the scribing processes. Lasers with the picosecond pulse duration were applied in structuring of conducting, semi-conducting and isolating films in the complex multilayered $\mathrm{Cu}(\mathrm{InGa}) \mathrm{Se}_{2}$ (CIGS) solar cells deposited on the polyimide substrate. The selective removal of ITO and CIGS layers was achieved with the $355 \mathrm{~nm}$ irradiation without a significant damage to the underneath layers in the ITO/CIGS/Mo/PI solar cell system. The $355 \mathrm{~nm}$ wavelength was also found to be favorable for the absorber film scribing process in the $\mathrm{ZnO} / \mathrm{CIGS} / \mathrm{Mo} / \mathrm{PI}$ solar cell system. High repetition rate picosecond lasers with a short pulse duration offer new possibilities for high quality and efficiency scribing.

DOI: 10.2961/jlmn.2010.01.0003
\end{abstract}

Keywords: CIGS thin films, solar cell, polymer substrate, picosecond laser, laser scribing, EDS

\section{Introduction}

Interest in complex multilayered $\mathrm{CuIn}_{\mathrm{x}} \mathrm{Ga}_{(1-\mathrm{x})} \mathrm{Se}_{2}$ (CIGS) solar cells has increased recently because of unique combination of factors. The manufacturing cost of thin-film cells can be very inexpensive since they require few raw materials and can be made by means of an efficient, scalable roll-to-roll process [1]. CIGS has been established as the most efficient thin-film technology in converting sunlight into electricity with the theoretical limit as high as $27 \%$ [2]. A flexible substrate will ultimately enable energy and building-integrated applications beyond the capability of rigid, heavier PV products.

Efficiency of the thin-film solar cells with a large active area might be maintained if small segments are interconnected in series in order to reduce photocurrent in thin films and resistance losses. The structuring is accomplished by three critical scribing processes called $\mathrm{P} 1, \mathrm{P} 2$, and $\mathrm{P} 3$. The P1 scribe must penetrate completely through the full thickness of the contact layer next to a substrate. This cut defines and isolates the individual cells with an effective resistance of tens of megaohms. The P2 scribe through the active layer is important for formation of the series interconnects between cells. The integrity and continuity of the P3 scribe are as critical as of P1 scribe. Cutting through both the top-contact and semiconductor layers, the P3 scribe isolates adjacent cells.

Selective removal of the films in multilayer structures of modern solar cells is crucial for performance of the devices. Lasers are the technology of choice for these processes, delivering the desired combination of high throughput and narrow, clean scribes [3]. Accuracy in the ablation depth and a high scribing speed are required for efficient and cost-effective production of solar cells of this type. Laser scribing rates have to be in the range of $2 \mathrm{~m} / \mathrm{s}$.
The main limiting factor for laser processing of the multilayer CuInSe $\mathrm{C}_{2}$ structures is deposition of molybdenum on walls of channels scribed in the films, and the phase transition of semi-conducting $\mathrm{CuInSe}_{2}$ to metallic state close to the ablation area due to the thermal effect [4]. Both effects shunt the photo-electric device and reduce its conversion efficiency. Thermal degradation of the CIGS solar cells starts at temperatures above $350^{\circ} \mathrm{C}$ due to diffusion of the buffer layer metal $(\mathrm{Cd}, \mathrm{Zn})$ into the absorber layer [5]. A large heat affected zone appears by using of nanosecond lasers, and nanosecond lasers are undesirable in manufacturing this type of photovoltaic elements. Femtosecond pulses are capable of ablating the films completely and selectively enough but their use is limited because of complexity in maintenance. According to the results of theoretical modeling, the processing without damage is possible with ultra-short-pulse lasers [6]. Picosecond lasers were tested in the CIS $\left(\mathrm{CuInSe}_{2}\right)$ solar cell layer scribing on polymers [7] and the glass substrate [8]. In case of the glass substrate and transparent electrode deposited on it, the back-side irradiation through the substrate with a carefully selected laser wavelength provides excellent material removal selectivity [3]. Polymers have quite high absorption in the visible spectral range [9] and direct irradiation of the films should be used.

An intensive process characterization has shown that low overlap of about $25 \%$ is desired during the scribing process in order to avoid peeling of the layers induced by the laser pulses [10].

Our goal is to develop the flexible and rapid laser technology for precise structuring of the CIGS solar cells compatible with the roll-to-roll production line. We used the laser with the picosecond pulse duration in scribing the mono-layer thin film structures deposited on glass $[11,12]$ and polymer substrates [9]. The experiments revealed po- 
tential of picosecond lasers in selective structuring of thin films when the wavelength of laser radiation was adjusted depending on optical properties both of the film and the substrate. Preliminary results of our research on the CIGS film scribing are presented in [13].

New results in application of laser scribing of two different multilayered CIGS solar cell systems with the transparent top-contacts made of ITO and $\mathrm{ZnO}$ are presented.

\section{Experimental}

Set-up for the laser scribing experiments included a laser, fast shutter, attenuator, harmonics generation modules, the beam expander, a few folding mirrors, an objective mounted on the $\mathrm{Z}$ stage, and the sample mounted on the XY stages. The picosecond laser PL10100 (10 ps, $100 \mathrm{kHz})$ made by Ekspla UAB was used in the ablation experiments. The picosecond laser was chosen for the experiments because the short pulse duration might prevent thermal damage and degradation of materials, enabling selective high quality ablation of the films. Nonlinear crystals were used for the wavelength conversion to UV radiation. An external Pockels cell was used for fast shuttering and pulse energy control. The beam expander stretched the beam, which was focused with the $\mathrm{f}=50 \mathrm{~mm}$ focusing lens. The positioning of the samples under the laser beam was performed with the XY stages Aerotech ALS1000. The focal position was controlled by moving the objective up and down with a stage Aerotech AVS105. Experimental set-up for laser structuring of the films is shown in Fig. 1.

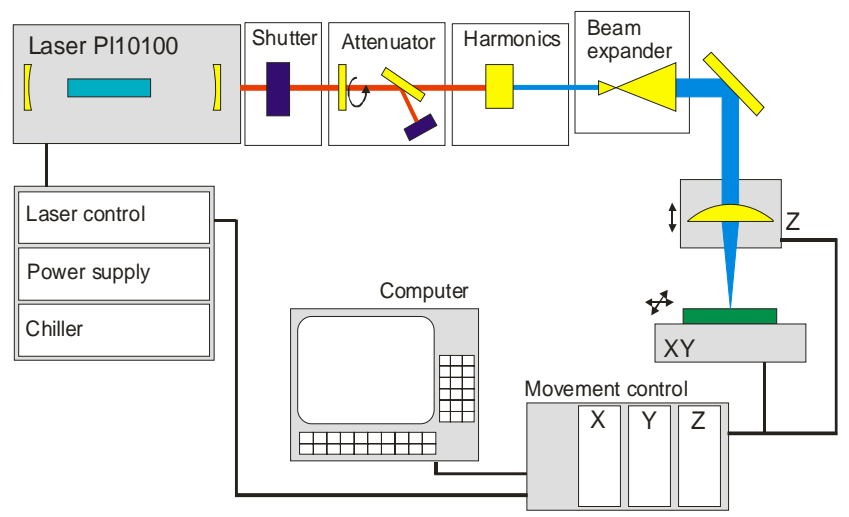

Fig. 1 Experimental set-up for laser scribing of the thin films.

The laser spot in focus plane depended on the wavelength used and was in the range of 15-25 $\mu \mathrm{m}$. Moreover, the laser fluence on the sample surface was affected because samples were flexible and it was difficult to maintain the exact position of the focal plane of the objective relative to the surface. An actual spot size on the surface was estimated from the ablated-area to laser-pulse-energy relationship [12]. The overlap along a scanning line was controlled by the translation speed at a constant pulse repetition rate. Various combinations of pulse energy, beam overlap and wavelength were used for selective ablation of the films. Optimal regimes for laser processing of every layer were estimated depending on the wavelength $(355 \mathrm{~nm}$ or $266 \mathrm{~nm}$ ). The beam overlap played an important role in the processing selectivity because the ablation threshold was sensitive to accumulation of the irradiation dose.
The quality of processing was evaluated with an optical microscope and the scanning electron microscope (SEM) JSM 6490LV (JEOL). Profiles of the laser ablated holes and trenches and chemical composition of the resulting surfaces were controlled with SEM EVO 50 XVP (Zeiss) with the X-ray energy dispersion spectrometer (EDS).

Polyimide (PI) film with the thickness of $25 \mu \mathrm{m}$ was used as a substrate. The films of molybdenum back-contact $(0.5 \mu \mathrm{m})$ and the whole structure of the CIGS solar cell deposited on the polymer substrates were used in the experiments. Two types of complete multilayer structure of the CIGS solar cells were investigated: with a thick topcontact made of ITO $(2 \mu \mathrm{m})$ and a thin top-contact made of $\mathrm{ZnO}: \mathrm{Al}(60 \mathrm{~nm})$. The absorber layer of the $\mathrm{CuIn}_{\mathrm{x}} \mathrm{Ga}_{(1-\mathrm{x})} \mathrm{Se}_{2}$ was $1 \mu \mathrm{m}$ thick in both cases. Most of the samples were provided by Solarion AG, Germany.

\section{Laser scribing of thin films for CIGS solar cells}

\subsection{Scribing of the molybdenum back-contact on poly- imide}

As the polymer film used as a substrate is badly transparent, the back-contact is made of the metal film, preferably molybdenum, directly deposited on the substrate. A homogeneous film of the metal should be divided into isolated stripes by local removal of the film in the process called P1. Good isolation between the nearby contact lines and the diminishing effect on the substrate are the main requirements at this stage. Back-side irradiation is not possible as in case of a glass substrate [8].

As the ablation thresholds of molybdenum and polyimide were close to each other at a high beam overlap, the experiments were limited to a high translation speed when only a few laser pulses affected the same area of the film [13]. Moreover, a high processing speed is preferable for the application. Removal of the metal film by evaporation from the polymer substrate with a low melting temperature, tended to damage the substrate by the high intensive center of the laser spot. The main benefit of the processing molybdenum film using the UV radiation was clean edges of trenches without remarkable melt formation (Fig.2).

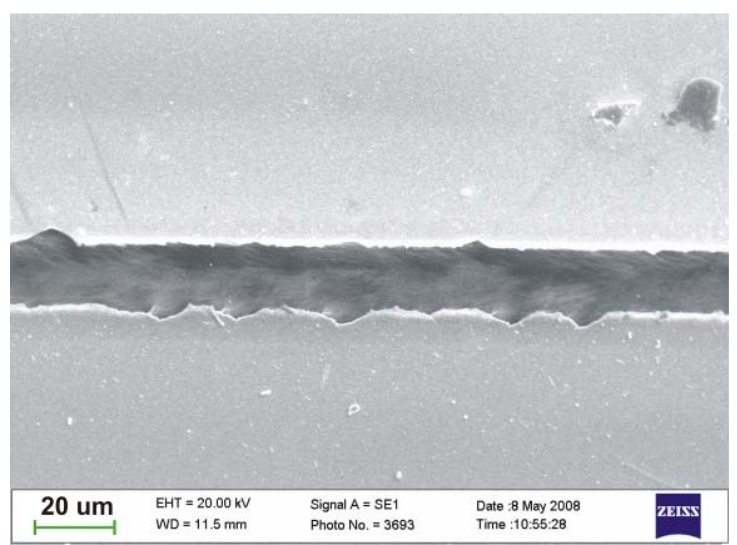

Fig. 2 SEM pictures of the P1 scribe in the molybdenum film. (Laser: $\lambda=355 \mathrm{~nm}, 2.35 \mathrm{~W}, 100 \mathrm{kHz}$; translation speed $600 \mathrm{~mm} / \mathrm{s}$ ).

As the Gaussian spatial profile of the laser beam was used in experiments, central part of the laser spot tended to penetrate into the polyimide film. Flattening of the profile should help to remove the layer smoothly. 


\subsection{Selective scribing in ITO/CIGS/Mo/PI structure with a "thick" top-contact}

The light absorbing layer of $\mathrm{CuIn}_{\mathrm{x}} \mathrm{Ga}_{(1-\mathrm{x})} \mathrm{Se}_{2}$ deposited on the back-contact should be structured making parallel trenches in it. We used a complete structure of layers in our experiments to estimate the processing regimes. The aim at this stage was to remove all the top layers, including CIGS and to expose the molybdenum back-contact.

The first experiments included ablation of craters with 10 laser pulses with different pulse energies in series. Ten pulses corresponded to the value of the laser beam overlap when the quality of trenches was the best without a significant damage of the polyimide substrate. The samples were investigated with SEM using the X-ray electron dispersion spectrometer because visual contrast did not allow discrimination of differences in chemical composition of layers. Fig.3. presents comparison of the SEM pictures with the EDS maps of spatial distribution of particular chemical elements in a close surrounding of the laser-made craters.

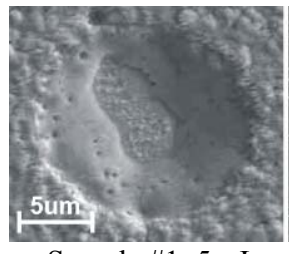

Sample \#1, $5 \mu \mathrm{J}$

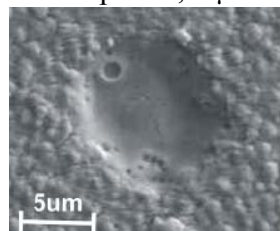

Sample \#2, $3.5 \mu \mathrm{J}$

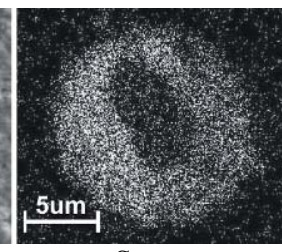

$\mathrm{Se}$

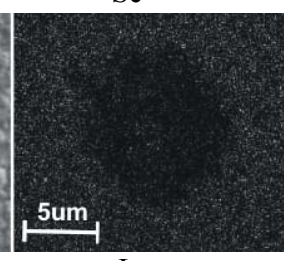

In

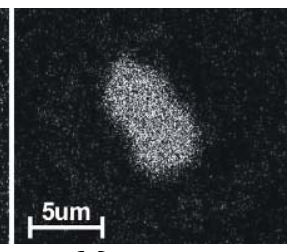

Mo

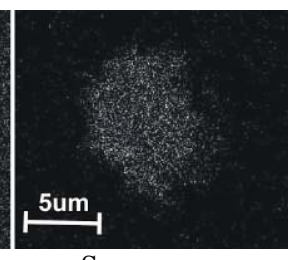

$\mathrm{Se}$
Fig. 3 SEM pictures and EDS maps of the craters ablated with 10 laser pulses with the energy of $5 \mu \mathrm{J}$ and $3.5 \mu \mathrm{J}$. (Laser: $\lambda=1064 \mathrm{~nm})$.

By ablating with the pulse energy of $3.5 \mu \mathrm{J}$, concentration of indium decreased and a signal from Se atoms appeared at the center of the crater. The top layer of conducting ITO was evaporated and the CIGS layer was exposed. Use of higher pulse energy $(5 \mu \mathrm{J})$ exposed the CIGS layer in a larger area but in the central part of the crater, where the laser intensity was higher, the whole material was evaporated and molybdenum back-contact was exposed. At the pulse energy of $20 \mu \mathrm{J}$, carbon atoms from the polymer were found in EDS spectra.

Table 1 Regimes of selective removal of layers and cutting of the CIGS multilayer structure. (Laser: $\mathrm{P}=2.35 \mathrm{~W}$, $\lambda=355 \mathrm{~nm}, 100 \mathrm{kHz}$ )

\begin{tabular}{ccl}
\hline Regime & $\begin{array}{l}\text { Scanning } \\
\text { speed, mm/s }\end{array}$ & Process \\
\hline$\# 1$ & 900 & $\begin{array}{l}\text { Removal of the ITO film } \\
\text { Exposition of the Mo back- } \\
\text { contact (P3) }\end{array}$ \\
$\# 3$ & 150 & $\begin{array}{l}\text { Isolation trench down to the } \\
\text { polyimide foil } \\
\text { Cutting of the CIGS multilayer }\end{array}$ \\
\hline
\end{tabular}

The UV laser radiation $(355 \mathrm{~nm})$ was also used to selectively scribe trenches in layers of the CIGS solar cell structure. The process parameters are presented in Table 1. Keeping the laser parameters the same and varying only the translation speed it was possible to find out the regimes of laser structuring in CIGS multilayer system:

- to evaporate the upper electro-conducting layer of ITO;

- to remove the semiconducting film and expose the molybdenum back-contact ( $\mathrm{P} 3$ process);

- to make an isolation trench by laser ablation of all films down to the polyimide substrate (edge isolation process);

- to cut a complete structure of the CIGS solar cell together with the substrate.

SEM pictures of trenches ablated in CIGS structure at different regimes and distribution of main chemical components in the cross-section of trenches are shown below. The top-layer of ITO as well as the thin buffer layers of $\mathrm{ZnO}$ and $\mathrm{CdS}$ were removed at regime \#1 cleanly (Fig.4). The $\mathrm{Se}$ and $\mathrm{Cu}$ signals were detected with the EDS at the bottom of the trench with a synchronous decrease in the concentration of In. The elements formed the absorber layer. Molybdenum and carbon were found at the background level.
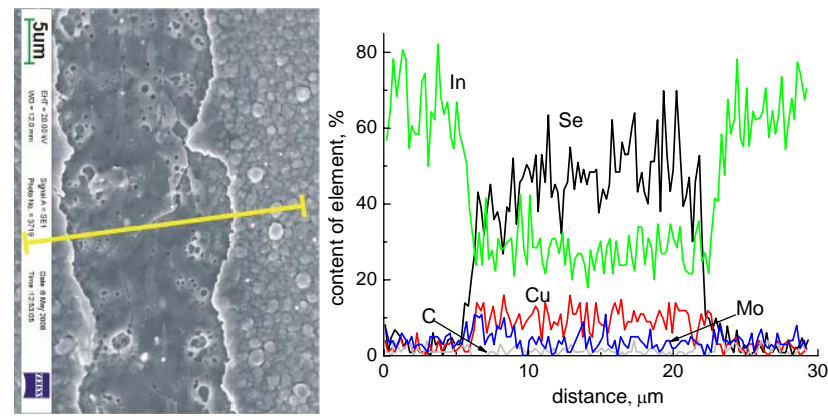

Fig. 4 SEM picture and EDS profile of a trench ablated in the ITO top layer to expose the absorber film. (Laser: $2.35 \mathrm{~W}, \lambda=355 \mathrm{~nm}, 100 \mathrm{kHz}$; translation speed $900 \mathrm{~mm} / \mathrm{s}$ ).

ITO has low absorption for the $355 \mathrm{~nm}$ radiation and thermal exfoliation prevailed [11]. The surface of the CIGS layer shows some sings of melting in the central part of the trench. As the properties of the surface of CIGS strongly depend on the bulk stoichiometry [14], heating might affect electrical properties of CIGS and special photoelectrical experiments are planned for verification.

When the translation speed was reduced to $380 \mathrm{~mm} / \mathrm{s}$ keeping all other processing parameters the same (Fig. 5), the laser was able to evaporate a CIGS film and expose the Mo back-contact. The high signal of Mo atoms was detected with the EDS in the central part of the trench.
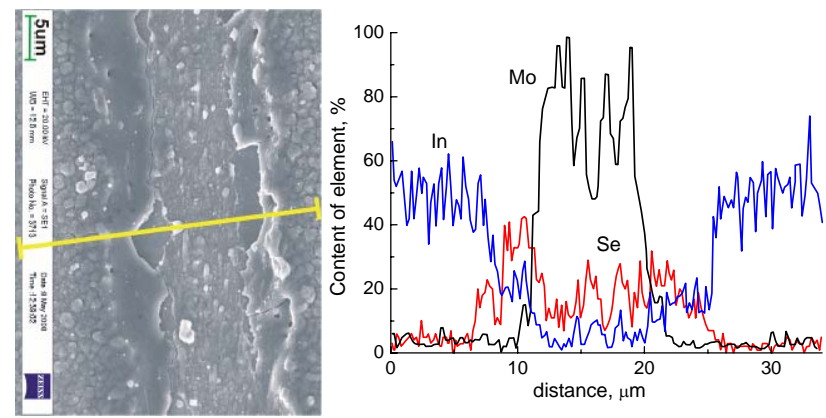

Fig. 5 SEM picture and EDS profile of a trench ablated down to the Mo layer to expose the back-contact. (Laser: $2.35 \mathrm{~W}$, $\lambda=355 \mathrm{~nm}, 100 \mathrm{kHz}$; translation speed $380 \mathrm{~mm} / \mathrm{s}$ ). 
The trenches had no sharp edges. This is a consequence of the Gaussian spatial distribution of energy in the laser beam. Slopes of the trenches were formed of partially removed layers and included $\mathrm{CuIn}_{\mathrm{x}} \mathrm{Ga}_{(1-\mathrm{x})} \mathrm{Se}_{2}$ at the bottom as quite strong signals of Se were detected with EDS. The trenches were narrow enough to ensure dense dislocation of separation lines between elements in solar cells. The upper layer of the top-contact was not affected outside the irradiation area.

A quite slow translation speed was used to cut the whole CIGS/substrate structure with the picosecond laser. Cuts of this kind are not required in the real production cycle, but the EDS investigations of a cross-section provided information about the quality of laser processing. SEM picture of the cross-section of the multi-layer CIGS structure is shown in Fig.6.
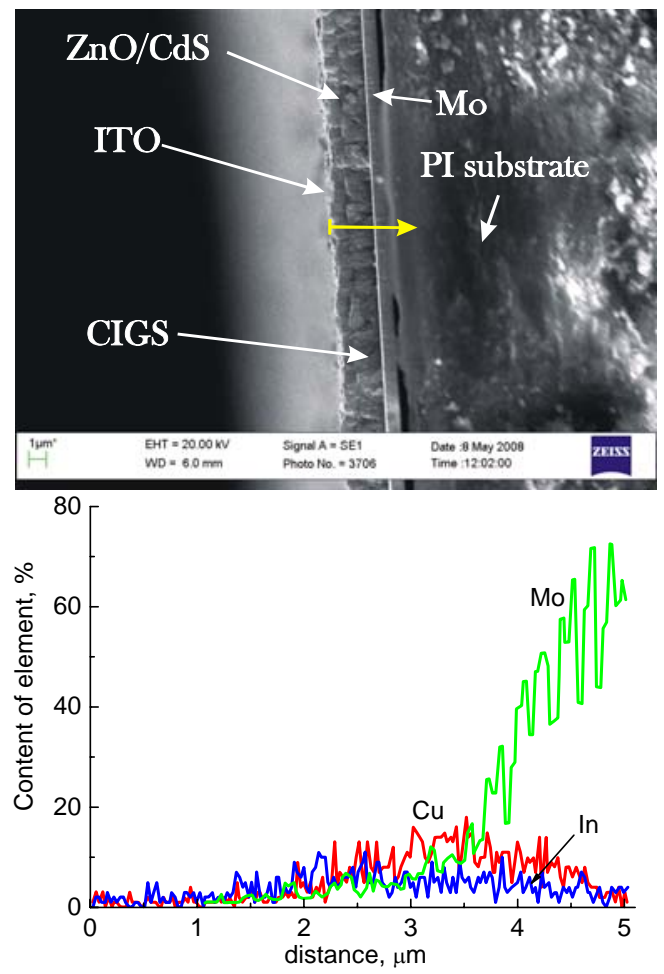

Fig. 6 Cross-section of the CIGS photovoltaic element cut with the laser and its chemical composition estimated by EDS. Arrow indicates the EDS scan direction. Length of the arrow is $5 \mu \mathrm{m}$. (Laser: $2.35 \mathrm{~W}, \lambda=355 \mathrm{~nm}$, $100 \mathrm{kHz}$; translation speed $35 \mathrm{~mm} / \mathrm{s}$ ).

Separate layers can be easily recognized in the picture, which means that there was no mixing during the deposition cycle and the laser processing did not disturb regular position of the layers with sharp edges. J. Hermann et al. [6] estimated that processing of CIGS solar cells with nanosecond lasers resulted in spreading of molybdenum over the CIGS film creating shorts. The picosecond pulse duration was short enough to prevent extensive formation of the melt and no mixing of Mo with CIGS was found. The EDS signals of the main chemical components of CIGS were measured along the cut depth (indicated by arrow in Fig. 6). Atoms of molybdenum appeared in EDS spectra on the edge of the Mo layers and were spread towards the polyimide substrate (Fig.6). The rise in the Mo concentration was at the same depth where concentrations of $\mathrm{In}$ and $\mathrm{Cu}$ atoms decreased.

\subsection{Selective scribing in $\mathrm{ZnO} / \mathrm{CIGS} / \mathrm{Mo} / \mathrm{PI}$ structure with a "thin" top-contact}

Shortage of indium production and its scarcity in the Earth challenge search for new materials that can be used as transparent, electro-conductive layers instead of the indium-tin oxide (ITO) for technical application. $\mathrm{ZnO}$ doped with aluminum is a good alternative to ITO. The second type of CIGS solar cell system used in our research was produced with the top-contact made of $\mathrm{ZnO}: \mathrm{Al}$. The thickness of the layer was small, only $60 \mathrm{~nm}$, in comparison with $2 \mu \mathrm{m}$ of the ITO layer in the previous section. We concentrated on the P3 process, scribing of the films to open the molybdenum back-contact. The Gaussian beam of the picosecond laser was used with the wavelengths of radiation equal to $355 \mathrm{~nm}$ and $266 \mathrm{~nm}$. Fig. 7 shows results of scribing with the $355 \mathrm{~nm}$ radiation depending on the mean laser power. Grains of CIGS remained in the trench at the low laser power, while the laser fluence in the central part was able to crack and exfoliate the molybdenum film at the high laser power.
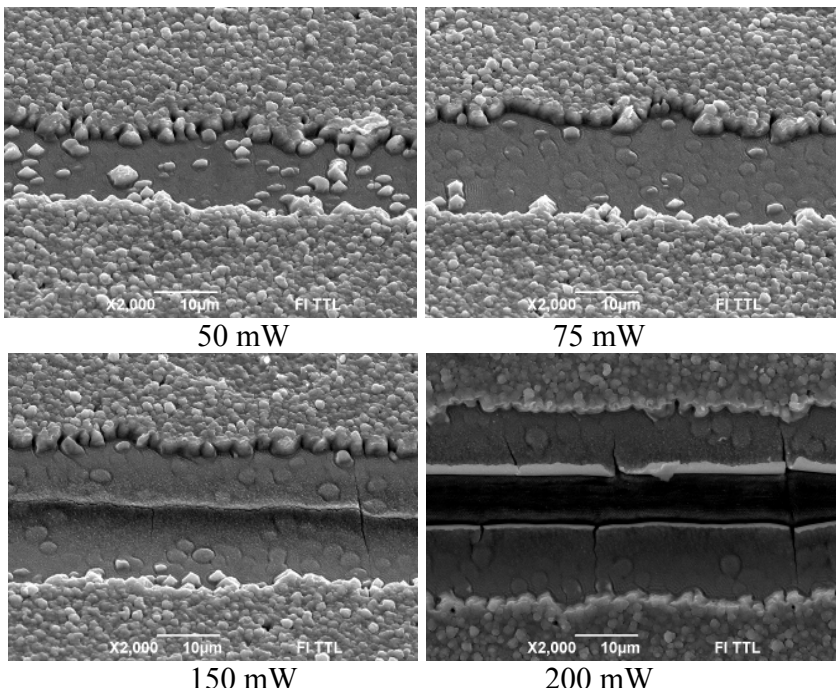

$200 \mathrm{~mW}$

Fig. 7 The $\mathrm{P} 3$ scribe in $\mathrm{ZnO} / \mathrm{CIGS} / \mathrm{Mo} / \mathrm{PI}$ versus laser power ( $355 \mathrm{~nm}, 50 \mathrm{kHz}, 300 \mathrm{~mm} / \mathrm{s}, 1 \mathrm{scan})$.

Results of laser scribing with the $266 \mathrm{~nm}$ radiation versus a number of scans are shown in Fig.8.

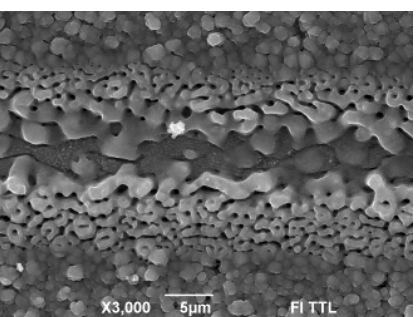

10

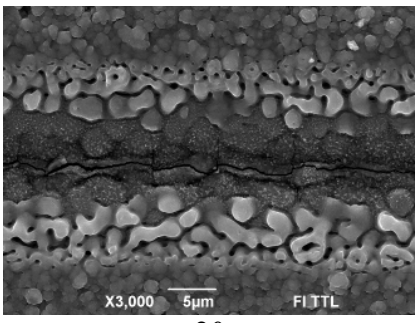

20

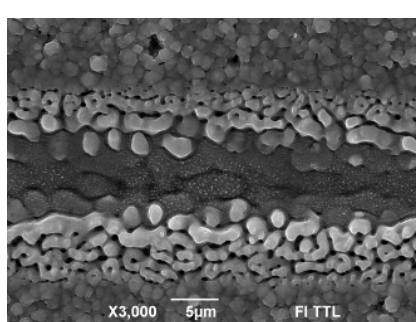

16

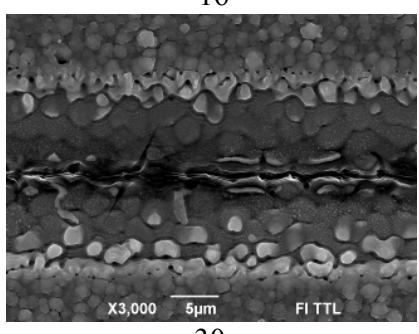

30
Fig. 8 The $\mathrm{P} 3$ scribe in $\mathrm{ZnO} / \mathrm{CIGS} / \mathrm{Mo} / \mathrm{PI}$ versus a number of scans $(266 \mathrm{~nm} .50 \mathrm{kHz}, 200 \mathrm{~mm} / \mathrm{s}, 65 \mathrm{~mW})$. 
The $266 \mathrm{~nm}$ laser radiation had high absorption in the $\mathrm{ZnO}$ layer. Therefore, the energy was initially coupled by the film itself. The CIGS film was ablated partially at every scan. However, the tails of the Gaussian beam affected the CIGS grains. Transformations in the layer structure are evident from Fig. 8. The excessive number of scans led to the damage of the molybdenum layer underneath.

Optimization of the P3 scribing process in the $\mathrm{ZnO} / \mathrm{CIGS} / \mathrm{Mo} / \mathrm{PI}$ solar cell system was possible only using the $355 \mathrm{~nm}$ laser radiation. Sharp edges of the trenches without damaging the metal film were achieved by removal of the CIGS grains (Fig. 9).

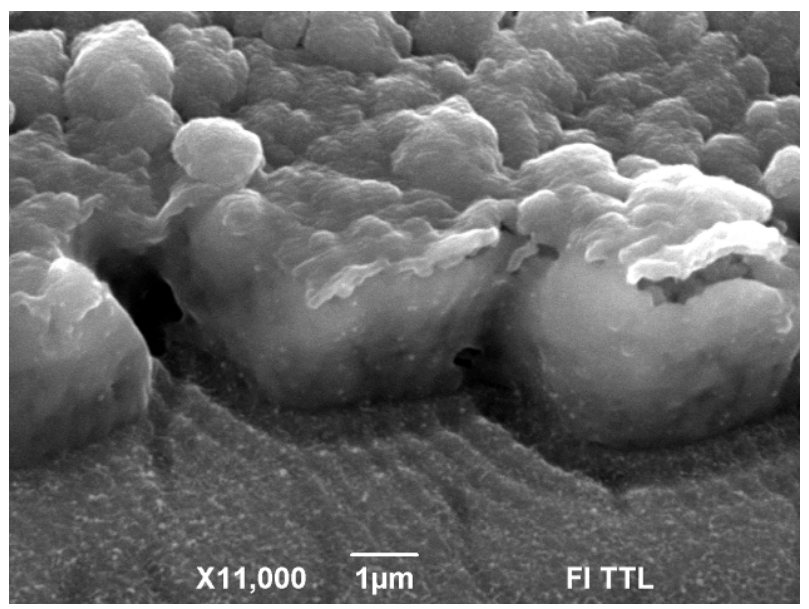

Fig. 9 Close view of edge of the $\mathrm{P} 3$ scribe in $\mathrm{ZnO} / \mathrm{CIGS} / \mathrm{Mo} / \mathrm{PI}$ with the $355 \mathrm{~nm}$ radiation at optimized parameters.

Better quality of processing with the $355 \mathrm{~nm}$ radiation compared with the $266 \mathrm{~nm}$ radiation was confirmed by the EDS profiles of the laser scribes (Fig. 10).

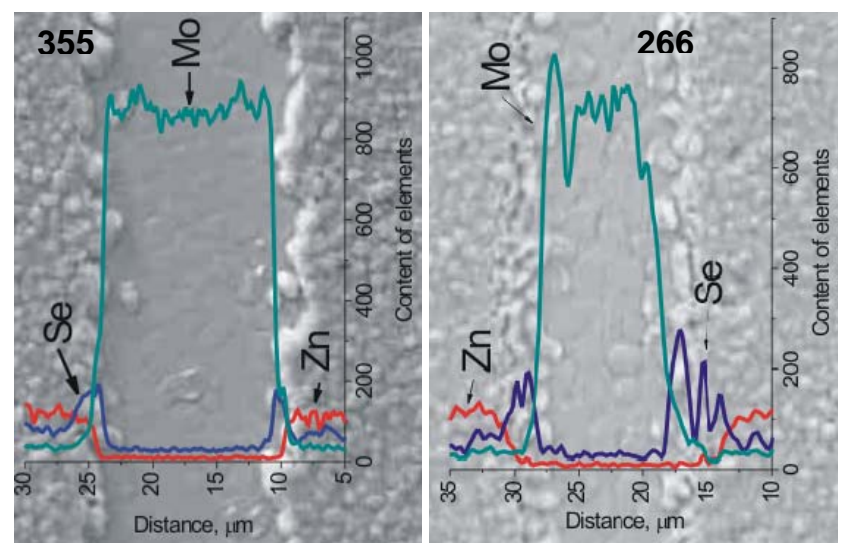

Fig. 10 SEM picture and EDS profiles of the P3 scribe in CIGS: $355 \mathrm{~nm}$ v.s. $266 \mathrm{~nm}$ wavelength.

A clean trench was produced by the $355 \mathrm{~nm}$ radiation, and remains of Se atoms from the CIGS layer were found along the trench edges in a close area, as narrow as $2 \mu \mathrm{m}$. Transformation in the CIGS film structure after irradiation with the $266 \mathrm{~nm}$ wavelength led to an intermix of $\mathrm{ZnO}$ and CIGS layers.

\section{Discussions}

The P1 scribe through the conducting layer adjusted to the substrate is intended for the back-contact formation and must be complete across the entire width of the solar cell. Any defects can lower the isolation resistance and even potentially completely short the cells out of the series circuit [3]. The integrity of the substrate should also be maintained.

The front-side picosecond laser ablation of the molybdenum film from even the glass substrate in [8] produced micro-cracks in the metal layer, while the back-side processing with $50 \%$ overlap led to crack-free scribing. The high absorption of polyimide did not allow processing the films from the backside in our case. Therefore, ablating molybdenum with a high evaporation temperature from the polymer substrate was a challenging task. Removal of the metal film from the polymer substrate with a low melting temperature by the short-pulse evaporation tended to damage the substrate by the high intensive center of the laser spot. Melt-free edges of the scribes were obtained when the UV laser radiation $(355 \mathrm{~nm})$ was applied.

The integrity of the P2 scribe is critical in forming the series interconnects between cells. Any active-layer material remaining over the contact layer will impose contact resistance, resulting in parasitic losses and decreased electrical power output of the module [3]. The CIGS layer is very sensitive to the exposure in the atmosphere [15], therefore the direct testing of the $\mathrm{P} 2$ process of the absorber layer stripping was not possible. Instead of this, opening of the back-contact by selective removal of all upper layers was used. The results are different for the solar cell systems with the thick ITO and a thin $\mathrm{ZnO}$ top-contact.

In the solar cell system with a thick ITO top-contact, the $355 \mathrm{~nm}$ laser radiation was mainly absorbed at the interface ITO/CIGS, and the most upper layer was removed by internal expansion of the materials in the process similar to "lift-off" rather than evaporation (P3 process - the front contact isolation). Selection of the right laser wavelength is important to keep the energy coupling in a well defined volume at the interlayer interface. Overlap of laser pulses should be carefully controlled to avoid micro-cracking and peeling of the top-contact layers induced by the laser pulses as it was found in case of amorphous silicon thin film solar cells in [10]. Reducing the translation speed increased ablation of the absorber layer. The clean scribing with sharp edges was not achieved because of the Gaussian distribution in the laser beam profile. Producing clean edges requires the use of flat-top shaped beam rather than a focused beam. Sometimes, a circular mask is used to aperture the central portion of the Gaussian laser beam so that the intensity exceeds the process threshold across the entire apertured beam [3]. However, the method leads to high energy losses at the aperture, and we continue our research with the specially reshaped laser beams.

In the solar cell system with a thin $\mathrm{ZnO}$ top-contact, it was possible to selectively ablate grains of the CIGS from the molybdenum back-contact when the $355 \mathrm{~nm}$ laser radiation was used. The sharpness of the scribe edges was confirmed by the EDS scans, where signals from the absorber layer were detected only in a very narrow range with a width of less than $2 \mu \mathrm{m}$. The $\mathrm{ZnO}$ top-contact was not affected even close to the rims of trenches. The reason could be an optimum relation between absorptance in CIGS and $\mathrm{ZnO}$ layers. Use of the $266 \mathrm{~nm}$ radiation led to extensive modification in both $\mathrm{ZnO}$ and CIGS layers with a quite wide intermix area spreading more than $5 \mu \mathrm{m}$ from the trench rims. 
The laser cutting through the full thickness of the CIGS solar cell including the substrate revealed that with picosecond lasers the molybdenum film was mainly evaporated without the extensive melt formation. The results are in contradiction to that of nanosecond laser ablation when residues of Mo were projected onto the walls of the ablation channels [6]. This shows potential of picosecond lasers to be applied in selective scribing of the CIGS solar cell. Conversion of the semiconducting $\mathrm{CuIn}_{\mathrm{x}} \mathrm{Ga}_{(1-\mathrm{x})} \mathrm{Se}_{2}$ to metallic phase might appear due to thermal input to the remaining material even using ultra-short laser pulses. The features cannot be found out with the used analysis techniques and photo-electrical properties of the laserprocessed CIGS structures should be checked.

Laser power in the range of hundred of miliwatts was used in most of the experiments. The high scribing speed of at least $2 \mathrm{~m} / \mathrm{s}$ can be reached by a multi-beam parallel processing with splitted laser beams.

\section{Conclusions}

Laser scribing with the picosecond pulse duration was applied in structuring the thin films deposited on the polyimide substrate. The wavelength of laser radiation was adjusted depending on optical properties both of the film and the substrate.

The selective removal of ITO and CIGS layers was achieved with the $355 \mathrm{~nm}$ radiation without a significant damage to the underneath layers in the ITO/CIGS/Mo/PI solar cell system. The $355 \mathrm{~nm}$ wavelength was also found to be favorable for the $\mathrm{P} 3$ scribing process in the $\mathrm{ZnO} / \mathrm{CIGS} / \mathrm{Mo} / \mathrm{PI}$ solar cell system.

The EDS analysis showed no residues of molybdenum projected onto the walls of the ablated trench due to the melt extrusion. Therefore, processing with picosecond lasers could not cause degradation of photo-electrical properties of the solar cells but verification is required.

Scribing of the thin film layers with the Gaussian beam profile caused damage in the center of the laser-machined trench. To avoid damage and increase the process productivity it is necessary to convert it to a flat top profile beam.

\section{Acknowledgments and Appendixes}

The work was supported by the Lithuanian State Science and Studies Foundation under project No B-31/2008. We express our thanks to Solarion AG, Germany, for support with the thin-film samples and Dr. K. Zimmer from the Leibniz-Institut für Oberflächenmodifizierung e.V., Leipzig for fruitful discussions.

\section{References}

[1] M. McIntyre, Photovoltaics International, 4, (2009) 93.

[2] T. Cheyney, Photovoltaics International, 1, (2008) 86.

[3] C. Dunsky, F. Conville, Proc. SPIE, 6871, (2008) 687129.

[4] A.D. Compaan, I. Matulionis, S. Nakade, Optics and Laser Engineering 34, (2000) 15.

[5] S. Kijima, T. Nakada, Jap. Appl. Phys. Express, 1, (2008) 075002

[6] J. Hermann, M. Benfarah, S. Bruneau, E. Axente, G. Coustillier, T. Itina, J-F. Guillemoles, P. Alloncle, J. Phys. D, 39, (2006) 453.
[7] D. Ruthe, K. Zimmer, T. Höche, Appl. Surf. Sci., 247, (2005) 447.

[8] H.P. Huber, M. Englmaier, C. Hellwig, G. Heise, A. Heiss, M. Kemnitzer, T. Kuznicki, R. Brenning, H. Vogt, J. Palm, Proc. of LIM'2009, Munich, June, 2009.

[9] G. Račiukaitis, M. Brikas, G. Darčianovas, D. Ruthe, K. Zimmer, Proc. of SPIE 6732, (2007) 67320C.

[10]S. Haas, A. Gordijn and H. Stiebig, Prog. Photovolt: Res. Appl. 16, (2008) 195.

[11] G. Račiukaitis, M. Brikas, M. Gedvilas, T. Rakickas, Appl. Surf. Sci., 253, (2007) 6584.

[12] G. Račiukaitis, M. Brikas, M. Gedvilas, G. Darčianovas, J. Laser Micro/Nanoengineer., 2, (2007) 1.

[13] P. Gečys, G. Račiukaitis, M. Gedvilas, A. Selskis, European Phys. J.: Appl. Phys., 46, (2009) 12508.

[14]A. Rockett, Thin Sol. Films, 361-2, (2000) 330.

[15]W.K. Metzger, I.L. Repins, M.A. Contreras, Appl. Phys. Lett., 93, (2008) 022110.

(Received: July 23, 2009, Accepted: December 10, 2009) 